\section{Psoriatic Arthritis Mutilans: Case Series and Literature Review}

To the Editor:

Psoriatic arthritis (PsA) is a seronegative spondyloarthropathy that develops in $1 \%$ to $39 \%$ of patients with psoriasis ${ }^{1}$. It may present clinically in different forms, including distal interphalangeal joint arthritis, asymmetrical oligoarthritis, symmetrical polyarthritis, spondylitis, and arthritis mutilans $(\mathrm{AM})^{2}$. Although $\mathrm{AM}$ accounts for less than $5 \%$ of all PsA, it undeniably represents the most severe and disabling form. Therefore, AM requires timely diagnosis and therapy aiming to prevent or block the irreversible destruction of small joints, mainly involving distal interphalanges of digits and toes. However, data on patients with such arthritis have been published as anecdotal reports or as very small series, so that the available information is sparse.
We describe a series of patients with delayed diagnosis of AM, and a systematic review of studies published in the last decade.

Case 1. A 77-year-old woman, with a 37-year history of psoriasis, was diagnosed with PsA at age 55 years when a symmetric polyarthritis involving both hands and feet occurred. She received longterm therapy with different nonsteroidal antiinflammatory drugs (NSAID) without significant improvement of arthritis, because she was intolerant to disease-modifying antirheumatic drugs (DMARD). She refused biological therapy. When significant deformity in phalanges of the left hand developed, she was referred to our ambulatory service. Biochemical tests revealed erythrocyte sedimentation rate (ESR) $50 \mathrm{~mm} / \mathrm{h}$, C-reactive protein (CRP) $5.84 \mathrm{~g} / 1$; clinical assessment showed pain score 70 on $100-\mathrm{cm}$ visual analog scale (VAS), Health Assessment Questionnaire (HAQ) score 1.75, swollen joint count $(\mathrm{SJC})=6$, tender joint count $(\mathrm{TJC})=5$, and $\mathrm{DJC}=5$. Figure 1A illustrates AM involving the hands. We suggested biologic

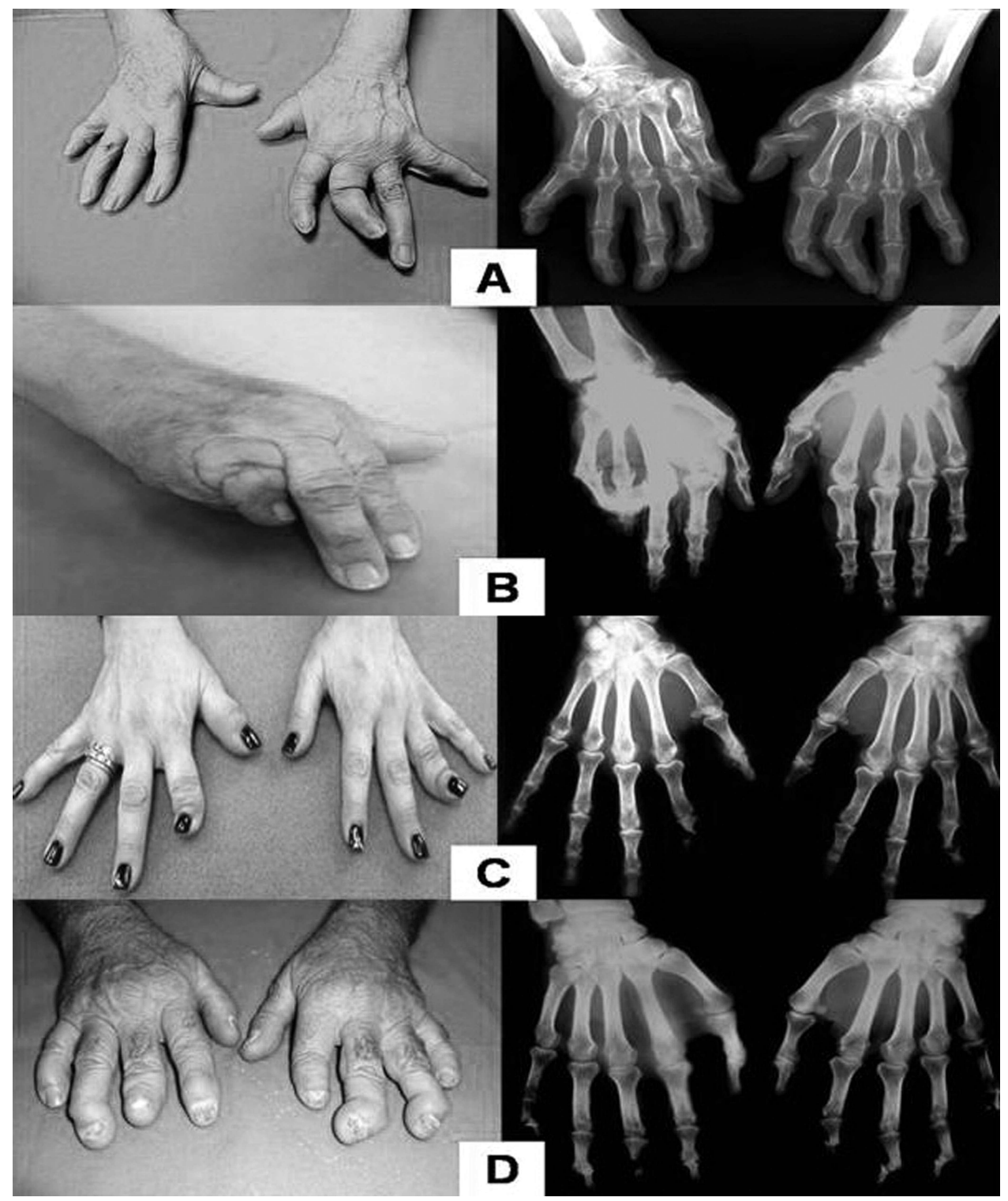

Figure 1. Destructive involvement of distal interphalangeal (DIP) joints and subluxation of the metacarpophalangeal joints (A). Mutilation of fourth and fifth digits of the right hand (B). Destructive involvement of the DIP joints, with telescoping of second finger of the right hand and fourth finger of the left hand (C). Shortening of third finger of right hand and second finger of left hand, and subluxation of DIP joints; onycholysis is also evident (D). 
therapy with an anti-tumor necrosis factor- $\alpha$ (anti-TNF- $\alpha$ ) agent, but she declined treatment.

Case 2. A 74-year-old woman developed psoriasis at the age of 20 years and arthritis when she was 45 years old, with both axial and peripheral involvement. Therapy with indomethacin $50 \mathrm{mg}$ daily achieved adequate control of arthritis-associated pain, so that no other therapies were performed. However, she was referred to our center with the following measures: ESR $43 \mathrm{~mm} / \mathrm{h}, \mathrm{CRP} 2.39 \mathrm{~g} / \mathrm{l}$, VAS for pain 50, HAQ score 1.25, $\mathrm{SJC}=5, \mathrm{TJC}=3$, and DJC $=4$. Figure $1 \mathrm{~B}$ shows the patient's hands with AM. She refused treatment with a biologic therapy despite information on the potential benefits for cutaneous and rheumatic manifestations.

Case 3. A 62-year-old woman with a 25-year history of psoriasis was diagnosed with PsA at age 50 years. She was irregularly treated with DMARD and with some cycles of etanercept, which she discontinued because of an "intolerance." Consequently, she remained without any therapy for several months. At clinical assessment, ESR was $25 \mathrm{~mm} / \mathrm{h}$, $\mathrm{CRP} 1 \mathrm{~g} / \mathrm{l}$, VAS for pain $=30, \mathrm{HAQ}$ score $=0.75, \mathrm{SJC}=2, \mathrm{TJC}=2$, and $\mathrm{DJC}=3$. Figure $1 \mathrm{C}$ shows her hands. She declined reintroduction of biologic therapy.

Case 4. A 70-year-old man with psoriasis at age 40 years developed arthritis involving the hands when he was 63 years old. He had previously received NSAID with nonsignificant control of pain, but no DMARD therapy. Referred to our clinic, he provided a radiograph with features of $\mathrm{AM}$ of the hands (Figure 1D). We undertook biochemical tests to start an appropriate therapy, but the patient was lost to followup.

Literature review. A literature search was performed in PubMed with MeSH terms "psoriatic arthritis mutilans" and "opera-glass hand" for the period January 2002 to December 2012. Only studies in which clinical data of patients with AM were specifically reported were extracted. Full articles of all relevant studies were retrieved, and manual searches of reference lists from these articles were performed, identifying 14 suitable studies (Figure $2)^{3,4,5,6,7,8,9,10,11,12,13,14,15,16}$. Including our series, a total of 120 patients with AM are described (Table 1). It was impossible to extrapolate data for 37 other AM cases reported in 5 studies because they were cumulatively described among other patients with PsA ${ }^{17,18,19,20,21}$. There was a weak prevalence of the male sex, with male/female ratio being 1.29. Duration of psoriasis and PsA before diagnosis of AM ranged from 10 to 52 years and 6 to 35 years, respectively; acute onset of AM (3 months) was reported in 1 patient $^{9}$. In 4 cases, psoriatic AM was associated with Charcot-like joint disease $^{6}$, while 1 patient presented with an axial bone proliferation causing cervical myelopathy ${ }^{12}$. In the largest $\operatorname{series}^{3}$, the AM was significantly associated with arthritis duration, involvement of distal phalanges, and reduced functional capacity. The prevalence (55\%) of psoriatic nail involvement in AM did not differ from that of other psoriatic patients ${ }^{3}$. A study found that bone edema, erosion, and proliferation on magnetic resonance imaging (MRI) were significantly more severe in the patients with AM than in controls ${ }^{4}$.

Therapy with 1 or more DMARD was performed before AM diagnosis in all but 1 patient, although such therapy was carried out irregularly in the majority of cases. Following AM diagnosis, biologic therapy with etanercept was performed in 6 cases (Table 1). The functional capacity improved significantly in 3 cases, with recovery of some movements allowing patients to make a fist and to walk easily ${ }^{7}$. Of note, therapy provided a stable bone disease without onset of new mutilation, as documented by radiographic features at 2-year followup in 2 other cases ${ }^{14}$. Unfortunately, no followup is available for the remaining AM patient treated with etanercept ${ }^{13}$.

AM involves fewer than $5 \%$ of patients with $\mathrm{PsA}^{1}$, the disease being particularly infrequent in Asian countries. Recent studies found an AM prevalence ranging from $1.5 \%$ to $4.9 \% 18,20,21$. AM represents an aggressive form of arthritis characterized by marked erosion of small joints of hands and feet, progressing to irreversible joint disruption. The resulting finger and toe mutilations severely impair patients' functional capacity. Much more effort is required to diagnose those patients whose PsA is progressing toward mutilation in an earlier stage. Development of AM has been associated with a longer arthritis duration, involvement of distal phalanges, and impaired functional capacity ${ }^{3}$, suggesting these patients should undergo tight disease control and therapy. Radiological assessment of joints may be useful for clinical management of PsA. A study found that as

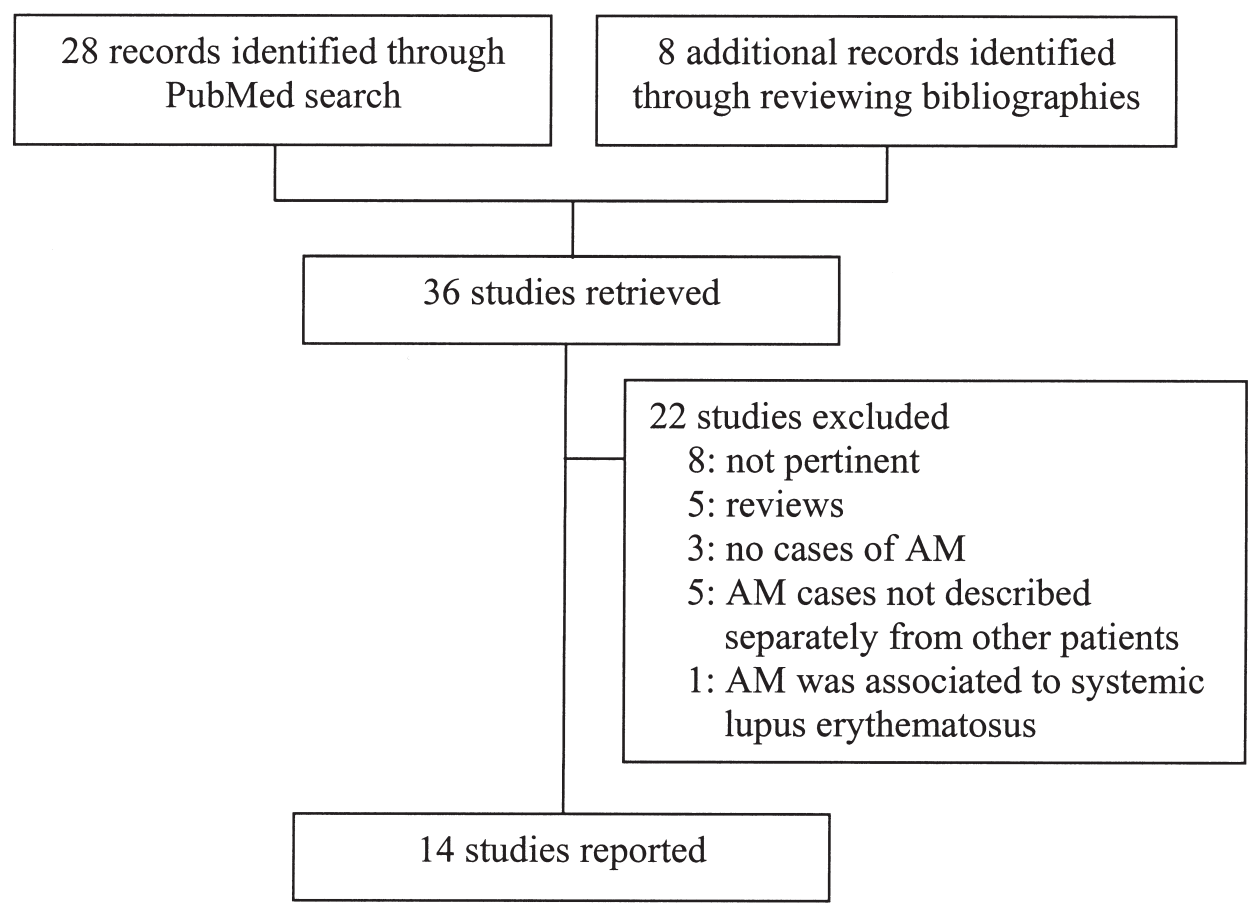

Figure 2. Identification of studies of arthritis mutilans (AM). 
Table 1. Clinical characteristics of patients with arthritis mutilans (AM) reported in the last decade.

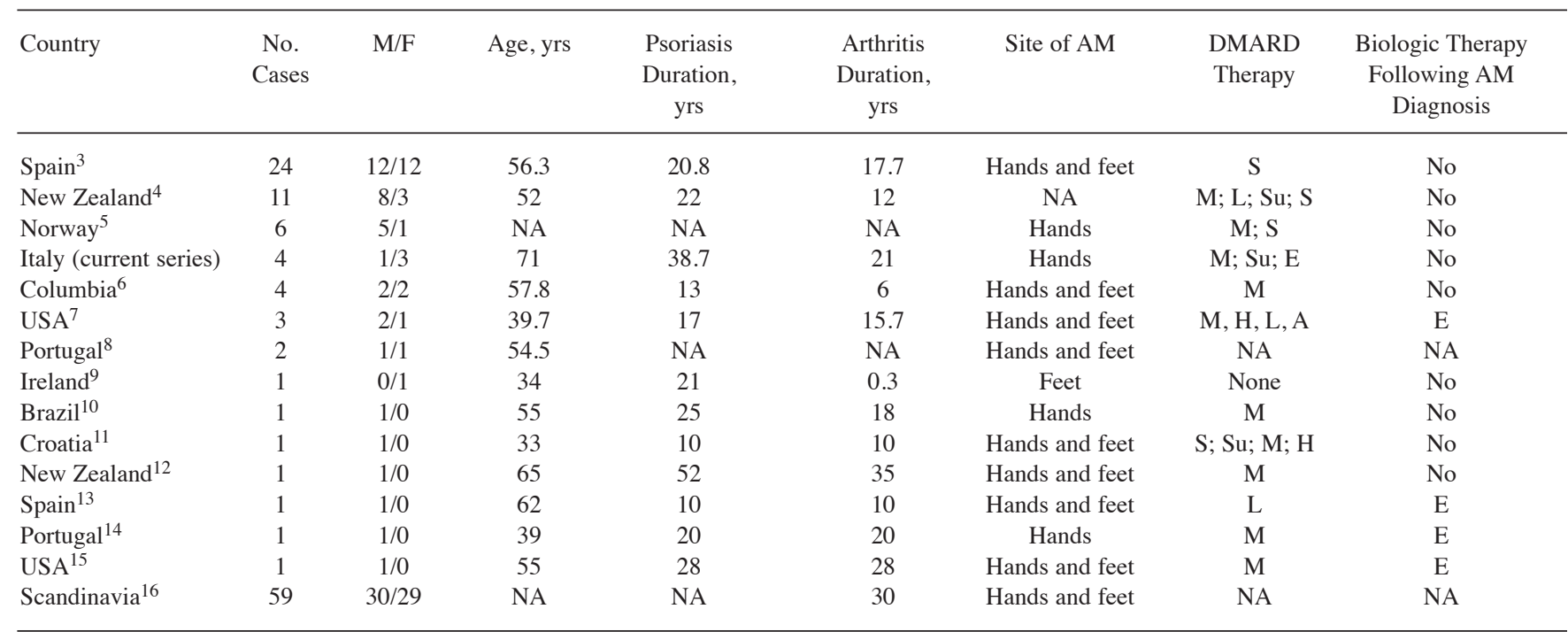

DMARD: disease-modifying antirheumatic drug; A: azathioprine; H: hydroxychloroquine; L: leflunomide; M: methotrexate; S: steroid; Su: sulfasalazine; E: etanercept; NA: not available.

many as $23 \%$ of patients with PsA have damage at the initial visit that was not detectable at clinical examination ${ }^{22}$. Similarly, it has been found that joint erosions are detectable at early radiographic assessment in nearly $50 \%$ of patients, i.e., within 2 years of arthritis ${ }^{23}$. Another study found that bone edema, erosions, and proliferation assessed with MRI scans were significantly more severe in patients with psoriatic AM than in those with other forms of PsA, suggesting that bone edema visible on MRI may be a pre-erosive feature of arthritis ${ }^{4}$. Thus, it is possible to diagnose early joint alterations in psoriatic patients in advance of their clinical manifestation.

An early treatment may prevent joint damage and irreversible finger destruction. A trial showed that structural joint damage in patients with PsA was significantly prevented by infliximab therapy, and that even a 6-month delay in starting such therapy was associated with a lower therapeutic gain $^{18}$. A dramatic repair of joint damage has been observed in a patient with PsA following 2 years of etanercept therapy, with fill-in and disappearance of typical destructive erosions in both fingers and toes ${ }^{24}$. Similar observations were described by others in clinical practice ${ }^{25}$.

Thus, biologic therapy may reduce radiologic progression and possibly induce regression of erosive damage in such patients. Such therapy could prevent or significantly delay the development of AM, but data for this remain scarce. Our review included 6 cases in whom the etanercept therapy was performed after AM diagnosis, that is, when both joint and bone alterations were already irreversible. However, the absence of progression at 2-year followup would suggest that such therapy may be beneficial even in these cases. In 1 patient from our series, etanercept was administered before onset of AM, but only a few irregular therapeutic cycles were administered because of patient refusal, so no reliable conclusions can be drawn from that case.

Different guidelines suggest that psoriatic patients with peripheral arthritis should receive anti-TNF- $\alpha$ therapy (grade A) or DMARD (grade B) following failure of NSAID ${ }^{26}$. Unfortunately, all our patients declined consent for such therapy. In our practice, such diffidence is much less evident in patients with other rheumatic diseases or inflammatory bowel diseases. Speculatively, it cannot be excluded that a general reluctance of these patients to accept effective drugs, including biologic agents, may be a factor for the development of AM.

$\mathrm{AM}$ is an infrequent but highly disabling form of PsA. Based on our findings, therapy with DMARD seems unable to prevent its development. A potential role for biologic therapy is expected, and prospective studies are urged.
VINCENZO BRUZZESE, MD; CINZIA MARRESE, MD; LORENZO RIDOLA, MD; ANGELO ZULLO, MD, Departments of Internal Medicine, Rheumatology, and Gastroenterology, Nuovo Regina Margherita Hospital, Via E. Morosini 30, 00153 Rome, Italy. Address correspondence to Dr. Bruzzese; E-mail: vinbruzzese@tiscali.it

\section{REFERENCES}

1. Cantini F, Piccoli L, Nannini C, Kaloudi O, Bretoni M, Cassarà E. Psoriatic arthritis: a systematic review. Int J Rheum Dis 2010;13:300-17.

2. Taylor W, Gladman D, Helliwell P, Marchesoni A, Mease P, Mielants H. The CASPAR Study Group. Classification criteria for psoriatic arthritis: development of new criteria from a large international study. Arthritis Rheum 2006;54:2665-73.

3. Rodriguez-Moreno J, Bonet M, Del Blanco-Barnusell J, Castaño C, Clavaguera T, Mateo-Soria L, et al. Mutilating/resorptive arthritis. A study of 24 patients in a series of 360 patients with psoriatic arthritis. Reumatol Clin 2013;9:38-41.

4. Tan YM, Østergaard M, Doyle A, Dalbeth N, Lobo M, Reeves Q, et al. MRI bone oedema scores are higher in the arthritis mutilans form of psoriatic arthritis and correlate with high radiographic scores for joint damage. Arthritis Res Ther 2009;11:1-9.

5. Nossent JC, Gran JT. Epidemiological and clinical characteristics of psoriatic arthritis in northern Norway. Scand J Rheumatol 2009;38:251-5.

6. Candia L, Cuellar ML, Marlowe SM, Marquez J, Iglesias A, Espinoza LR. Charcot-like arthropathy: a newly-recognized subset of psoriatic arthritis. Clin Exp Rheumatol 2006;24:172-5.

7. Pomerantz RG, Mody E, Husni ME, Qureshi AA. Follow-up of psoriasis arthritis mutilans patients treated with anti-TNF-alfa therapy. J Drugs Dermatol 2009;8:406-12.

8. Ribeiro A, Costa J, Bogas M, Costa L, Araújo D. Forma mutilante de artrite psoriatica [Mutilans psoriatic arthritis]. Acta Reumatol Port 2009;34:290-1.

9. Bell L, Murphy CL, Wynne B, Cunanne G. Acute presentation of arthritis mutilans. J Rheumatol 2011;38:174-5.

10. Appel da Silva F, Appel da Silva MC, Romagna ES. Clinical images: psoriatic arthritis mutilans. Arthritis Rheum 2010;62:2159.

11. Vrogic P, Pašic A, Podobnik-Takac T. Psoriasis vulgaris and arthritis psoriatica gravis mutilans. Acta Dermatovenerol Croat 
2003;11:22-8.

12. Ly J, Pinto C, Doyle A, Dalbeth N, McQueen FM. Axial bone proliferation causing cervical myelopathy in the mutilans form of psoriatic arthritis despite peripheral bone erosion. Ann Rheum Dis 2009;68:443-4.

13. González-Nieto JA, López-Montes L, Gallego-García F, Tugues-Roure JM. Psoriatic arthritis mutilans. Rev Clin Esp 2012;212:e87.

14. Peixoto D, Teixeira F, Bogas M, Costa J, Araújo D. Biologic therapy in psoriatic arthritis mutilans. Acta Reumatol Port 2011;36:189-90.

15. Gaffar M. Arthritis mutilans in a patient with psoriasis. Hospital Physician 2002;10:46-50.

16. Gudbjornsson B, Ejstrup L, Gran JT, Iversen L, Lindqvist U, Paimela L, et al. Psoriatic arthritis mutilans (PAM) in the Nordic countries: demographics and disease status. The Nordic PAM study. Scand J Rheumatol 2013 Mar 21. [E-pub ahead of print]

17. Yamamoto T, Yokozeki H, Nishioka K. Clinical analysis of 21 patients with psoriasis arthropathy. J Dermatol 2005;32:84-90.

18. van der Heijde D, Kavanaugh A, Gladman D, Antoni C, Krueger GG, Guzzo C, et al. Infliximab inhibits progression of radiographic damage in patients with active psoriatic arthritis through one year of treatment. Arthritis Rheum 2007;56:2698-707.

19. Soy M, Karaca N, Umit EU, Bes C, Piskin S. Joint and nail involvement in Turkish patients with psoriatic arthritis. Rheumatol Int 2008;29:223-5.
20. Reich K, Kruger K, Mossner R, Augustin M. Epidemiology and clinical pattern of psoriatic arthritis in Germany: A prospective interdisciplinary epidemiological study of 1511 patients with plaque-type psoriasis. Br J Dermatol 2009;160:1040-7.

21. Helliwell PS, Porter G, Taylor WJ, for The CASPAR Study Group. Polyarticular psoriatic arthritis is more like oligoarticular psoriatic arthritis, than rheumatoid arthritis. Ann Rheum Dis 2007;66:113-7.

22. Khan M, Schentag C, Gladman DD. Clinical and radiological changes during psoriatic arthritis disease progression. J Rheumatol 2003;30:1022-6.

23. Kane D, Pathare S. Early psoriatic arthritis. Rheum Dis Clin North Am 2005;31:641-57.

24. Eder L, Chandran V, Gladman DD. Repair of radiographic joint damage following treatment with etanercept in psoriatic arthritis is demonstrable by 3 radiographic methods. J Rheumatol 2011:38:1065-70

25. Garcia-Valladares I, Cuchacovich R, Espinoza LR. Psoriatic arthritis: Radiographic joint repair following etanercept therapy [letter]. J Rheumatol 2012;39:185.

26. Ritchlin CT, Kavanaugh A, Gladman DD, Mease PJ, Helliwell P, Boehncke WH, et al. Treatment recommendation for psoriatic arthritis. Ann Rheum Dis 2009;68:1387-94.

J Rheumatol 2013;40:7; doi:10.3899/jrheum.130093 